\title{
Antioxidant and Antimicrobial Effects of Pistacia lentiscus L. Extracts in Pork Sausages
}

\author{
George Botsaris, Antia Orphanides, Evgenia Yiannakou, Vassilis Gekas and Vlasios Goulas* \\ Cyprus University of Technology, Department of Agricultural Sciences, Biotechnology and Food Science, \\ CY-3603 Lemesos, Cyprus \\ Received: January 7, 2015 \\ Accepted: July 2, 2015
}

\begin{abstract}
Summary
Pistacia lentiscus fruits are ingredients of traditional Cypriot sausages. The objective of this study is to evaluate P. lentiscus extracts as natural additives to the sausages. First, the phenolic content and antioxidant activity of fruit and leaf extracts were determined. Results revealed that leaves are richer source of polyphenolic antioxidants than fruits, with methanol being the better extraction solvent. In the next step, the antioxidant and antimicrobial effects of methanolic extracts $(300 \mathrm{mg} / \mathrm{kg}$ ) in the pork sausage formulation were investigated. Peroxide, acid and thiobarbituric acid-reactive substance values demonstrated that both fruit and leaf extracts reduced the rate of lipid oxidation of sausages at $4{ }^{\circ} \mathrm{C}$. Total viable count revealed significant differences on the fifth day of storage, with better microbial inhibition by leaf extract. No significant differences between the extracts were observed after the tenth day of storage. Overall, the extracts can be used to prevent lipid oxidation and reduce microbial spoilage during the first days of storage of fresh traditional pork sausages.
\end{abstract}

Key words: lipid oxidation, mastic tree, natural antioxidants, phenolic compounds, plant extracts, total viable count

\section{Introduction}

Nowadays, the food industry is constantly seeking natural, safe and low-cost antioxidant and antimicrobial agents in an attempt to replace synthetic additives. This growing interest is mainly attributed to (i) the plethora of epidemiological studies that has demonstrated the inverse association between the risk of chronic diseases such as cancer and cardiovascular diseases and the consumption of fruits and vegetables, (ii) the concerns regarding the safety of the chronic consumption of synthetic compounds traditionally used as preservatives in foods and beverages, and (iii) the public's conviction that natural antioxidants are safer than their synthetic analogues. In these efforts, research has been focused on herbs, spices and medicinal plants, since they provide an extraordinary reservoir of phytochemicals with diverse bioactivities (1).
In meat and poultry products, several ingredients of plant origin such as spices (rosemary, oregano, etc.), fruits (plums, pomegranate, blueberry, etc.) and food industry wastes have been evaluated as potential food additives $(2,3)$. The plant extracts are mainly used in an attempt to prevent lipid and protein oxidation and/or to inhibit the bacterial and yeast growth, therefore providing protection against deterioration and spoilage $(4,5)$. Their antioxidant and antimicrobial effects have been mainly correlated with their high phenolic content (6). In addition, pure phytochemicals such as phenolic acids, flavonoids, diterpenes and tocopherols have been tested as natural additives in meat products $(7,8)$.

Pistacia lentiscus (Anacardiaceae) known as mastic tree, one of the many evergreen bushes found in the eastern Mediterranean region has a long history in folk medicine dating from the times of the ancient Greeks (9). Fruits, 
resins and leaves of $P$. lentiscus have been used to treat many diseases $(10,11)$. The potent antioxidant and antimicrobial properties of its extracts have been highlighted and are associated with the presence of flavonoids and phenolic acids (12). The ripe P. lentiscus L. fruits are also ingredients of traditional Cypriot sausages due to their unique and characteristic taste, but their antioxidant and antimicrobial effects on pork sausages have not been studied yet.

The aim of the present study is to evaluate Pistacia lentiscus L. fruit extract as a food additive to control lipid oxidation and investigate potential effects on total viable count of fresh pork sausages during storage at $4{ }^{\circ} \mathrm{C}$. Furthermore, the antioxidant and antimicrobial activities of $P$. lentiscus L. leaf extracts in sausages were also evaluated since they are a plant material easily available at low cost, which could possibly exhibit similar bioactive properties. Four different solvents were evaluated (water, methanol, butanol and acetone) in an attempt to determine the best extraction method.

\section{Materials and Methods}

\section{Plant material and reagents}

Ripe fruits and leaves of Pistacia lentiscus L. were collected from village Pachna (Lemesos, Cyprus; $34^{\circ} 46^{\prime} \mathrm{N}$ $\left.32^{\circ} 47^{\prime} \mathrm{E}\right)$. The plant material was air-dried at room temperature in the dark until constant mass and kept in glass dispensers.

Standards of gallic acid, caffeic acid, rutin, ( \pm )-6-hydroxy-2,5,7,8-tetramethylchromane-2-carboxylic acid (Trolox), and 1,1,3,3-tetramethoxypropane (TMP) were purchased from Sigma-Aldrich (St. Louis, MO, USA). Folin-Ciocalteu reagent, sodium carbonate, 1,1-diphenyl-2-picrylhydrazyl (DPPH) radical, sodium acetate, 2,4,6-Tris(2-pyridyl)-striazine (TPTZ), iron(III) chloride, 2,2'-azino-bis(3-ethylbenzothiazoline-6-sulfonic acid) diammonium salt (ABTS), potassium persulphate, potassium iodate, phenolphthalein, sodium hydroxide, trichloroacetic acid, 2-thiobarbituric acid and all other common reagents and solvents were also obtained from Sigma-Aldrich.

\section{Preparation of $P$. lentiscus extracts}

A mass of $3 \mathrm{~g}$ of fruits or leaves was extracted with $100 \mathrm{~mL}$ of each solvent (water, methanol, butanol and acetone). The mixtures were placed for $20 \mathrm{~min}$ in an ultrasonic bath (Raypa UCI-50, 35 KHz; R. Espinar, S.L., Terrassa, Barcelona, Spain). Then, the mixtures were filtered under vacuum and the solvents were evaporated to dryness using a rotary evaporator. The yield of the extraction of leaves and fruits was 12.0 and $14.1 \%$, respectively.

\section{Sausage preparation}

Pork sausages were prepared as described by Georgantelis et al. (7). Boneless pork meat from the shoulder and pork belly fat were obtained from the local retail market. Pork meat and pork belly were cut into cubes and stored for $24 \mathrm{~h}$ in cold storage in order to drain excessive drip. The raw materials were comminuted separately and then mixed at a ratio to achieve a fat content of $((25 \pm 1) \%)$. Sausages also contained salt $(23 \mathrm{~g} / \mathrm{kg})$, corn oil $(6 \mathrm{~g} / \mathrm{kg})$ and the selected $P$. lentiscus extracts at a mass fraction of $300 \mathrm{mg} / \mathrm{kg}$. Then, the meat blend was stuffed into natural casings from the cleaned small intestine of pigs. The casings were rinsed with tap water and dipped in a lactic acid solution ( $3 \%$, by volume) for $15 \mathrm{~min}$ for tenderisation. The sausages were air-dried and placed in polyester trays, wrapped with air-permeable polyethene film and stored at $4{ }^{\circ} \mathrm{C}$. All treatments were repeated three times to remove any effects deriving from the initial quality of meat.

\section{Phenolic composition of plant extracts}

Determination of total phenolics of extracts using the Folin-Ciocalteu assay

The reaction mixture consisted of $0.5 \mathrm{~mL}$ of diluted extract, $5 \mathrm{~mL}$ of distilled water and $0.5 \mathrm{~mL}$ of the Folin-Ciocalteu reagent. After $3 \mathrm{~min}, 1 \mathrm{~mL}$ of saturated sodium carbonate solution was added. The mixture was thoroughly mixed, allowed to stand for $1 \mathrm{~h}$ at room temperature in the dark and the absorbance was measured at 765 $\mathrm{nm}$. Each measurement was repeated three times and total phenolic content was expressed in $\mathrm{mg}$ of gallic acid equivalents (GAE) per $\mathrm{g}$ of extract (13).

\section{Determination of phenolic compounds}

The determination of different polyphenolic classes was performed according to Obied et al. (14). Briefly, $1 \mathrm{~mL}$ of diluted extract was mixed with $1 \mathrm{~mL}$ of $0.1 \% \mathrm{HCl} / \mathrm{etha}-$ nol solution $(0.1 \mathrm{~mL}$ of $\mathrm{HCl}$ per $100 \mathrm{~mL}$ of $95 \%$ ethanol) and $8 \mathrm{~mL}$ of $2 \% \mathrm{HCl} /$ ethanol solution $(2 \mathrm{~mL}$ of $\mathrm{HCl}$ per $100 \mathrm{~mL}$ of $95 \%$ ethanol) in a $10-\mathrm{mL}$ volumetric flask. The absorbance was measured at 280, 320 and $360 \mathrm{~nm}$ in order to evaluate the mass fractions of total phenolics, hydroxycinnamic acid derivatives and flavonols, respectively. The corresponding standard curves for the above determinations were prepared using ethanolic solutions of gallic acid, caffeic acid and rutin, respectively.

\section{Antioxidant activity of plant extracts}

Determination of DPPH radical scavenging activity

A volume of $2 \mathrm{~mL}$ of each diluted extract was mixed with $1 \mathrm{~mL}$ of $\mathrm{DPPH}^{\bullet}$ solution $(0.3 \mathrm{mmol} / \mathrm{L})$. The absorbance of the mixture was measured after $30 \mathrm{~min}$ of incubation in the dark at $517 \mathrm{~nm}$ and the free radical scavenging activity was expressed in $\mathrm{mg}$ of Trolox equivalents (TE) per $g$ of extract (15).

Determination of total antioxidant activity by FRAP assay

A sample of $3 \mathrm{~mL}$ of freshly prepared ferric reducing antioxidant power (FRAP) solution $(0.3 \mathrm{~mol} / \mathrm{L}$ of acetate buffer, $\mathrm{pH}=3.6$, containing $10 \mathrm{mmol} / \mathrm{L}$ of TPTZ and 40 $\mathrm{mmol} / \mathrm{L}$ of $\mathrm{FeCl}_{3} \cdot 10 \mathrm{H}_{2} \mathrm{O}$ ) and $100 \mu \mathrm{L}$ of diluted extract were incubated at $37^{\circ} \mathrm{C}$ for $4 \mathrm{~min}$ and the absorbance was measured at $593 \mathrm{~nm}$. A standard curve of Trolox was prepared and the results were expressed in $\mathrm{mg}$ of TE per $\mathrm{g}$ of extract (15). 
Determination of ABTS radical scavenging activity

The ABTS radical cation solution was prepared by mixing $7 \mathrm{mM}$ of ABTS and $2.45 \mathrm{mM}$ of potassium persulphate for $16 \mathrm{~h}$ in the dark at room temperature. Then, ABTS solution was diluted with $80 \%$ ethanol to obtain an absorbance of $(0.700 \pm 0.005)$ at $734 \mathrm{~nm}$. A volume of $3.9 \mathrm{~mL}$ of ABTS solution was added to $0.1 \mathrm{~mL}$ of the extract. The reaction mixture was allowed to react for $10 \mathrm{~min}$ and the absorbance was measured at $734 \mathrm{~nm}$. The extracts were diluted to give $20-80 \%$ reduction of the blank absorbance. A standard curve of Trolox was used to express the results in $\mathrm{mg}$ of TE per $\mathrm{g}$ of extract (16).

\section{Determination of lipid oxidation}

Determination of peroxide value

A mass of $5 \mathrm{~g}$ of sausages was weighed into a $250-\mathrm{mL}$ Erlenmeyer flask, followed by the addition of $30 \mathrm{~mL}$ of the mixture of acetic acid and chloroform (3:2, by volume) and $0.5 \mathrm{~mL}$ of saturated potassium iodate solution. The mixture was allowed to react for $1 \mathrm{~min}$, then $30 \mathrm{~mL}$ of deionised water and $1 \mathrm{~mL}$ of starch solution, $1 \%$ by mass per volume, were added. The mixture was titrated with $0.01 \mathrm{M} \mathrm{Na}_{2} \mathrm{~S}_{2} \mathrm{O}_{3}$ until the blue colour disappeared. Results were expressed in $\mathrm{mmol}$ of $\mathrm{O}_{2}$ per $\mathrm{kg}$ of sausages (17).

Determination of acid value

The acid value was determined according to $Q i$ and Zhou (18). A mass of $5 \mathrm{~g}$ of sausages was mixed with 50 $\mathrm{mL}$ of neutralised ethyl alcohol and $0.5 \mathrm{~mL}$ of phenolphthalein indicator. The mixture was heated in water bath and then titrated using $0.1 \mathrm{~mol} / \mathrm{L}$ of $\mathrm{NaOH}$. Results were expressed in $\mathrm{mg}$ of $\mathrm{NaOH}$ per $\mathrm{g}$ of sausages.

\section{Determination of lipid oxidation by TBARS assay}

Thiobarbituric acid-reactive substances (TBARS) assay is the most common chemical method for the semiquantitative estimation of lipid oxidation in foods. A mass of $5 \mathrm{~g}$ of sausages was extracted with $30 \mathrm{~mL}$ of trichloroacetic acid ( $7.5 \%$, by mass per volume). The solution was filtered and aliquots of $5 \mathrm{~mL}$ from the filtrate were transferred into tubes together with $5 \mathrm{~mL}$ of $0.02 \mathrm{M}$ 2-thiobarbituric acid. For the preparation of the blank sample, 5 $\mathrm{mL}$ of 2-thiobarbituric acid and $5 \mathrm{~mL}$ of trichloroacetic acid $(7.5 \%$, by mass per volume) were mixed. The reaction was performed in a water bath at $100{ }^{\circ} \mathrm{C}$ for $40 \mathrm{~min}$. Then, the absorbance was read at $538 \mathrm{~nm}$. A standard curve of 1,1,3,3-tetramethoxypropane (TMP) was prepared for the determination of malonaldehyde (17).

\section{Determination of the total viable count}

Plating and enumeration of the total viable count was performed using a modification of the method described by Lorenzo and Franco (19) and Botsaris and Taki (20). Briefly, from each batch of the three different sausages, $5 \mathrm{~g}$ were aseptically weighed and transferred into sterile stomacher bags, where they were mixed with $45 \mathrm{~mL}$ of sterile maximum recovery diluent (MRD; Thermo Fischer Scientific Oxoid, Basingstoke, UK) and homogenised in a stomacher for $1 \mathrm{~min}$. Serial dilutions (1:10) were prepared using the MRD down to $10^{-12}$. A volume of $0.1 \mathrm{~mL}$ of each dilution was inoculated and dispersed onto plate count agar (PCA; Oxoid) in duplicate and incubated at $30^{\circ} \mathrm{C}$ for 3 days (21). This analysis was repeated every five days for 25 days, starting from day 1 and the total viable count was determined.

\section{Statistical analysis}

Statistical analysis was carried out using the software package SPSS v. 20.0 (SPSS Inc., Chicago, IL, USA) and the comparison of average values of each treatment was based on the analysis of variance (one-way ANOVA) according to Tukey's test at significance level of $5 \%(\mathrm{p} \leq 0.05)$.

\section{Results and Discussion}

\section{Phytochemical analysis and antioxidant properties of P. lentiscus extracts}

Mature fruits are used in traditional Cypriot sausages, but the leaves were also tested due to their low cost and availability throughout the year. Therefore, solvents of different polarity were used to prepare extracts from $P$. lentiscus fruits and leaves. Results showed that phenolic content of extracts was strongly affected by the solvent and plant material (Table 1). Methanol, a polar protic solvent, was the most suitable for the extraction of phenolic compounds from $P$. lentiscus plant materials among the studied solvents. This finding is in agreement with a previous study about the solubilisation preference of natural phenols to alcohols (22). The classification of the phenolic content also showed that these extracts contained significant amounts of flavonols (in fruits from $(8.0 \pm 0.1)$ to (33.1

Table 1. Total phenolics, hydroxycinnamates and total flavonols of Pistacia lentiscus leaf and fruit extracts

\begin{tabular}{|c|c|c|c|c|c|c|c|c|}
\hline \multirow{3}{*}{ Solvent } & \multirow{2}{*}{\multicolumn{2}{|c|}{$\frac{w\left(\text { total phenolics as GAE }{ }^{*}\right)}{\mathrm{mg} / \mathrm{g}}$}} & \multirow{2}{*}{\multicolumn{2}{|c|}{$\frac{\left.w \text { (total phenolics as } \mathrm{GAE}^{* *}\right)}{\mathrm{mg} / \mathrm{g}}$}} & \multirow{2}{*}{\multicolumn{2}{|c|}{$\frac{w(\text { hydroxycinnamates as CAE) }}{\mathrm{mg} / \mathrm{g}}$}} & \multirow{2}{*}{\multicolumn{2}{|c|}{$\frac{w \text { (total flavonols as RE) }}{\mathrm{mg} / \mathrm{g}}$}} \\
\hline & & & & & & & & \\
\hline & Leaves & Fruits & Leaves & Fruits & Leaves & Fruits & Leaves & Fruits \\
\hline Butanol & $(123.2 \pm 4.1)^{\mathrm{c}}$ & $(74.7 \pm 4.4)^{\mathrm{d}}$ & $(57.0 \pm 2.6)^{\mathrm{b}}$ & $(59.1 \pm 2.1)^{c}$ & $(8.4 \pm 0.3)^{c}$ & $(5.4 \pm 0.2)^{\mathrm{c}}$ & $(28.7 \pm 1.3)^{b}$ & $(8.0 \pm 0.1)^{\mathrm{d}}$ \\
\hline Acetone & $(353.7 \pm 4.5)^{\mathrm{b}}$ & $(178.1 \pm 7.8)^{\mathrm{c}}$ & $(183.6 \pm 7.0)^{\mathrm{a}}$ & $(110 \pm 2.7)^{b}$ & $(16.5 \pm 0.7)^{\mathrm{a}}$ & $(12.7 \pm 0.2)^{b}$ & $(34.6 \pm 1.3)^{a}$ & $(20.8 \pm 0.4)^{c}$ \\
\hline Methanol & $(414.9 \pm 3.0)^{\mathrm{a}}$ & $(449.3 \pm 6.1)^{\mathrm{a}}$ & $(173.7 \pm 5.2)^{\mathrm{a}}$ & $(244.2 \pm 8.8)^{\mathrm{a}}$ & $(15.5 \pm 0.4)^{\mathrm{a}}$ & $(22.2 \pm 0.8)^{\mathrm{a}}$ & $(29.9 \pm 0.7)^{b}$ & $(33.1 \pm 1.1)^{\mathrm{a}}$ \\
\hline Water & $(397.9 \pm 15.9)^{\mathrm{a}}$ & $(242.8 \pm 13.6)^{b}$ & $(168.5 \pm 5.4)^{\mathrm{a}}$ & $(117.6 \pm 5.7)^{\mathrm{b}}$ & $(11.5 \pm 0.6)^{\mathrm{b}}$ & $(14.2 \pm 0.8)^{\mathrm{b}}$ & $(20.1 \pm 1.1)^{c}$ & $(27.0 \pm 1.6)^{\mathrm{b}}$ \\
\hline
\end{tabular}

Total phenolics were determined by ${ }^{*}$ Folin-Ciocalteu method and ${ }^{* *}$ Obied's protocol

$\mathrm{GAE}=$ gallic acid equivalent, $\mathrm{CAE}=$ caffeic acid equivalent, $\mathrm{RE}=$ rutin equivalent

Values with different letters in superscript are significantly different at $\mathrm{p}<0.05$ 
1.1) and in leaves from $(20.1 \pm 1.1)$ to $(34.6 \pm 1.3) \mathrm{mg}$ of rutin equivalents (RE) per $g$ of extract) and hydroxycinnamates (in fruits from $(5.4 \pm 0.2)$ to $(22.2 \pm 0.8)$ and in leaves from $(8.4 \pm 0.3)$ to $(16.5 \pm 0.7) \mathrm{mg}$ of caffeic acid equivalents (CAE) per $\mathrm{g}$ of extract). Previous studies also reported that $P$. lentiscus leaves are rich in phenolics such as tannins and glucogallin, a gallic acid glucoside $(10,23)$. Overall, phenolic composition of extracts showed that methanolic extracts are the most promising extracts to determine their antioxidant effect in sausage lipid fraction.

The antioxidant activity of $P$. lentiscus extracts was evaluated using three in vitro assays, since an approach with multiple assays for the determination of antioxidant activity is highly advisable for natural products (24). DPPH and ABTS radical scavenging activities are based on the reduction of chromogenic radical by antioxidant/ reducing compounds (25). These assays showed that leaves are a richer source of antioxidants than fruits (Figs. $1 \mathrm{a}$ and $\mathrm{b}$ ). Both assays also suggested that the antioxidant activity of butanolic extracts was the lowest among the studied extracts. Furthermore, the highest antioxidant activity was measured in the methanol extract. In particular, the DPPH radical scavenging activity in fruits was from $(70.2 \pm 5.3)$ to $(387.6 \pm 16.8)$ and in leaves from $(123.9 \pm 7.7)$ to (510.3 \pm 6.6$) \mathrm{mg}$ of TE per $\mathrm{g}$ of extract, while the ABTS radical scavenging activity ranged from $(21.3 \pm 7.3)$ to $(290.2 \pm 28.1)$ $\mathrm{mg}$ of TE per $\mathrm{g}$ of extract in fruits and from $(92.4 \pm 3.9)$ to
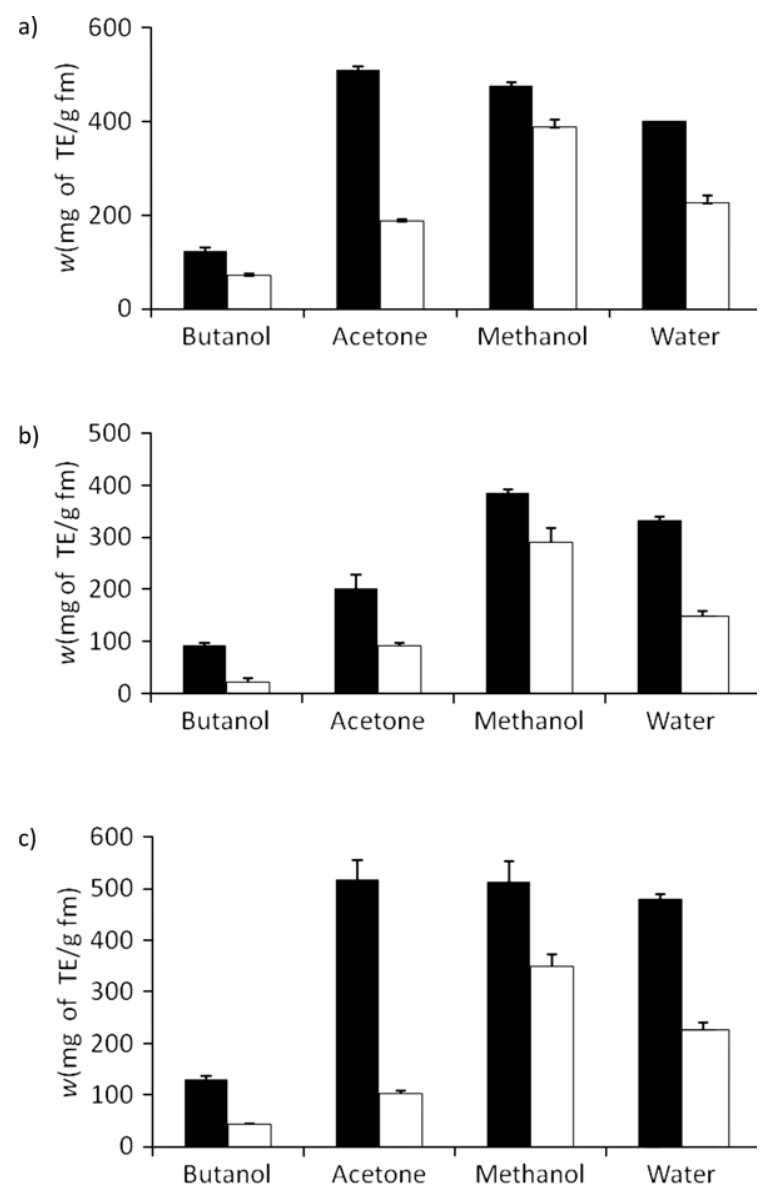

Fig. 1. Antioxidant activity of P. lentiscus fruit ( $\square$ ) and leaf ( $\square$ ) extracts as determined by: a) DPPH, b) ABTS, and c) FRAP assays. $\mathrm{TE}=$ Trolox equivalents, $\mathrm{fm}=$ fresh mass
(384.6 \pm 6.7$) \mathrm{mg}$ of TE per $\mathrm{g}$ of extract in leaves. FRAP assay measures the ability of antioxidants to reduce the ferric 2,4,6-tripyridyl-s-triazine complex [Fe(III)-(TPTZ) $\left.{ }_{2}\right]^{3+}$ to the intensely blue-coloured ferrous complex [Fe(II)$\left.(\mathrm{TPTZ})_{2}\right]^{2+}(25)$. A great diversity of antioxidant activities was found among the extracts (from $(42.2 \pm 2.4)$ to (518.8 \pm 37.2) $\mathrm{mg}$ of TE per $\mathrm{g}$ of extract). This assay also highlighted the superiority of methanol among the used solvents, and of the antioxidant activity of the leaf extracts, compared to fruits (Fig. 1c).

Overall, methanol was the most appropriate solvent to extract polyphenolic antioxidants from P. lentiscus materials. In addition, polar extracts may be more suitable to inhibit lipid oxidation compared to less polar extracts, since the theory of 'polar paradox' describes that polar antioxidants are more effective in non-polar substrates such as pork sausage lipids (26).

\section{The antioxidant effect of $P$. lentiscus extracts on pork sausage}

The potential of P. lentiscus extracts to prevent the oxidation of lipids in pork sausages was investigated using three methods (peroxide, acid and TBARS values). Peroxide value is used for monitoring the initial stages of autoxidation, the acid value is correlated with lipid rancidity (18), while TBARS quantifies the secondary products of lipid oxidation of unsaturated fatty acids (27). Results showed that peroxide values of all samples increased during storage at $4{ }^{\circ} \mathrm{C}$, as expected (Fig. 2a). In general, the rate of formation of peroxides in sausages enriched with $P$. lentiscus extracts was lower than in the sausages without the extract (control). After 20 days of storage at $4{ }^{\circ} \mathrm{C}$, peroxide values compared to the control sausages were 38.2 and $47.2 \%$ lower in sausages with leaf and fruit extract, respectively. Georgantelis et al. (7) also reported a reduction of 29.1 and $74.8 \%$ of peroxide values in sausages containing $\alpha$-tocopherol and rosemary extract, respectively, after 20 days cold storage. Statistical analysis showed no significant differences in the antioxidant effect of the two extracts during storage at $4{ }^{\circ} \mathrm{C}$.

The acid values were also determined since they are an indicator of lipid rancidity that affects odour and taste of meat products. Both triglycerides and phospholipids contribute to the development of rancidity, although the contribution of phospholipids is the most important (28). The acid value of control sausages increased progressively during cold storage; an increase of acid value was monitored during 20 days of storage at $4{ }^{\circ} \mathrm{C}$ (Fig. 2b). The acid value of sausages containing fruit extract changed less in the initial stages of storage and increased after 20 days of cold storage. On the other hand, the acid value of sausages enriched with leaf extract did not change during storage. Specifically, at 20 days of cold storage, the acid values of sausages containing fruit and leaf extract were 9 and 31 $\%$, respectively, lower compared to the control, highlighting the potential of leaf extract.

The measurement of TBARS demonstrated that the addition of $P$. lentiscus to pork sausages had a significant effect on their lipid oxidation. TBARS of control sausages increased during storage; the highest rate of TBARS formation was found between 10 and 15 days of cold storage 
in sausages with and without extract (Fig. 2c). On the 15th day, TBARS value of control sausages was $1741 \mathrm{mg} / \mathrm{kg}$, while sausages with fruit and leaf extracts had significantly lower TBARS values $(<869 \mathrm{mg} / \mathrm{kg})$. Results did not show any significant differences between leaf and fruit extracts.

Overall, peroxide and TBARS values showed that both fruit and leaf extracts prevented significantly the lipid oxidation of pork sausages. In addition, the acid value confirmed the strong antioxidant effect of the leaf extract, but the fruit extract did not inhibit lipid oxidation. This fact could be attributed to the presence of fatty acids such as oleic and linoleic acids in P. lentiscus fruit (29), which gives higher acidity to sausages with added fruit extracts.

\section{Antimicrobial effect of P. lentiscus extracts on pork sausage}

The results of the total viable count are graphically presented in Fig. 3 in the form of a box and whisker plot.
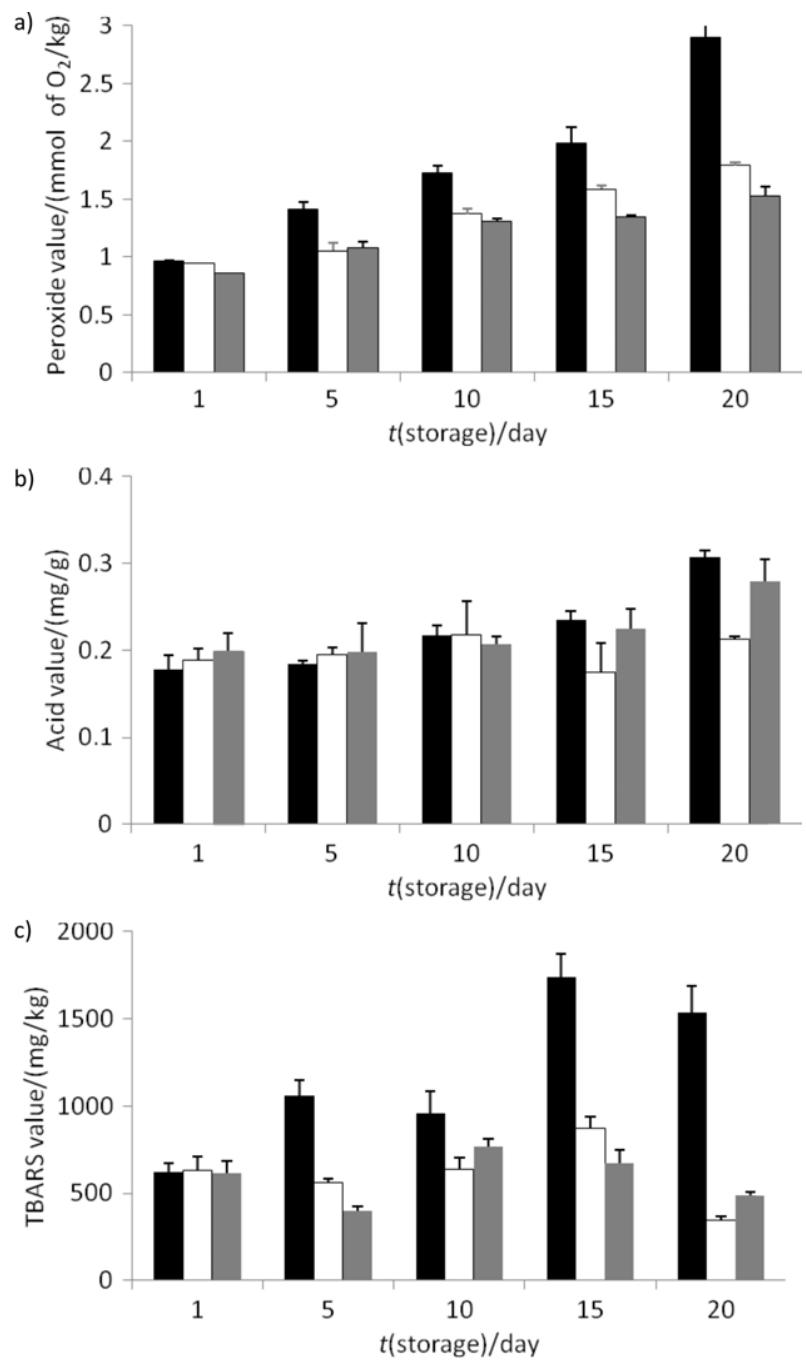

Fig. 2. Effect of P. lentiscus fruit and leaf extracts on pork sausage lipids as measured by: a) peroxide value, b) acid value, and c) TBARS value. ( $\bullet$ ) sausages without extract (control), ( $\square$ ) sausages with leaf extract, and ( $\square$ ) sausages with fruit extract

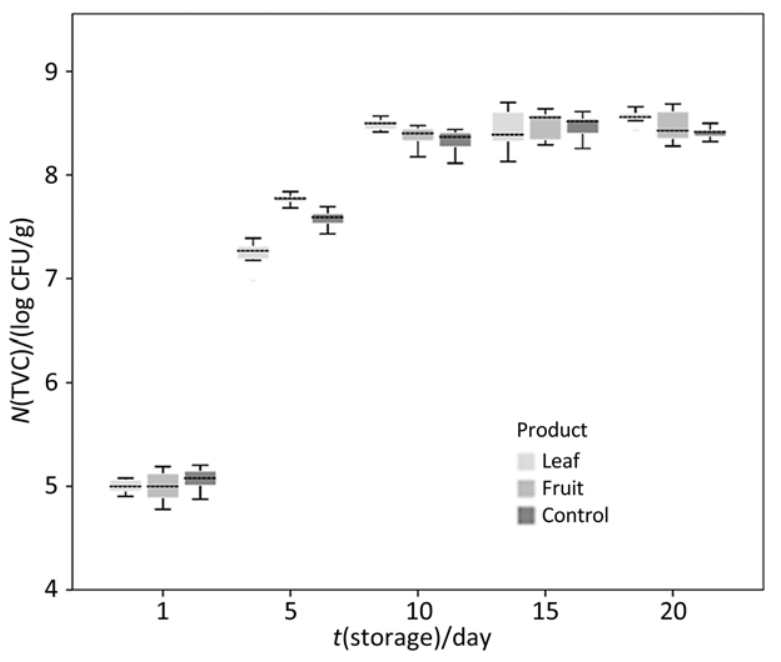

Fig. 3. Effect of $P$. lentiscus fruit and leaf extracts on total viable count (TVC) of pork sausages stored at $4{ }^{\circ} \mathrm{C}$

The box represents $50 \%$ of the population of each count and the remaining $50 \%$ is covered by the whiskers. The horizontal dotted line crossing the box represents the median value of each of the three different samples tested (leaf, fruit and control). The initial mean count of the control \pm standard error on day 1 was $(5.07 \pm 0.03) \log$ CFU/g. Sausages prepared with leaf and fruit extracts had initial counts on day 1 of $(5.00 \pm 0.02)$ and $(5.00 \pm 0.04) \log$ $\mathrm{CFU} / \mathrm{g}$, respectively. Analysis of variance revealed no significant differences between the initial counts $(p=0.145)$. At the second point of sampling, which was after five days of refrigerated storage, a statistically significant difference was observed between the samples $(\mathrm{p}<0.0005)$, with the sausage made with the leaf extract exposing the lowest total viable count of $(7.25 \pm 0.03) \log \mathrm{CFU} / g$. Statistically significant differences were not observed during storage at $4{ }^{\circ} \mathrm{C}$ for 10,15 and 20 days. On day 10 all samples had mean viable count above $8 \log \mathrm{CFU} / \mathrm{g}$, which was considered to be the threshold for microbial rejection of the sausages. At this point spoilage was visible in all samples, even those containing plant extracts. The addition of leaf extract was successful in inhibiting the growth of aerobic microorganisms during the first five days of storage. This is an important technological improvement of a product that usually has less than a week for display on the shelf. Previous research using extracts has also revealed important improvement of microbial quality (30), but in some cases the intense odour produced by the extract was a major drawback for the industrial application. In the case of the traditional sausages presented here, the application of the extract did not result in off-odours as P. lentiscus is a traditional additive to the sausage.

\section{Conclusions}

Phenolic content and antioxidant properties of Pistacia lentiscus are strongly affected by extraction solvent. In general, methanol was the most appropriate solvent to extract antioxidants from this plant material. The use of methanolic extracts as food additives in pork sausages inhibited significantly the lipid oxidation during storage at 
$4{ }^{\circ} \mathrm{C}$. On the other hand, the methanolic extracts reduced microbial spoilage of fresh traditional pork sausages in the initial stages of storage. Overall, although leaves were richer in phenolics than fruits, both extracts are an excellent source of natural antioxidants and are candidates as additives in sausages and meat products. This is the first time that $P$. lentiscus fruits and leaves have been evaluated as food additives in meat products. Further studies are needed to fractionate the extracts and to isolate individual compounds and/or fraction with potent antioxidant and antimicrobial activities.

\section{References}

1. Rehecho S, Hidalgo O, de Cirano MGI, Navarro I, Astiarasán I, Ansorena D, et al. Chemical composition, mineral content and antioxidant activity of Verbena officinalis L. LWT - Food Sci Technol. 2011;44:875-82. http://dx.doi.org/10.1016/j.lwt.2010.11.035

2. Karre L, Lopez K, Getty KJK. Natural antioxidants in meat and poultry products. Meat Sci. 2013;94:220-7. http://dx.doi.org/10.1016/j.meatsci.2013.01.007

3. Ruiz-Capillas C, Herrero AM, Tahmouzi S, Razavi SH, Triki M, Rodriguez-Salas L, et al. Properties of reformulated hot dog sausage without added nitrites during chilled storage. Food Sci Technol Int. (in press). http://dx.doi.org/10.1177/1082013214562919

4. Gallo M, Ferracane R, Naviglio D. Antioxidant addition to prevent lipid and protein oxidation in chicken meat mixed with supercritical extracts of Echinacea angistifolia. J Supercrit Fluids. 2012;72:198-204.

http://dx.doi.org/10.1016/j.supflu.2012.08.006

5. Zhang $\mathrm{H}$, Kong B, Xiong YL, Sun X. Antimicrobial activities of spice extracts against pathogenic and spoilage bacteria in modified atmosphere packages fresh pork and vacuum packages ham slices stored at $4{ }^{\circ} \mathrm{C}$. Meat Sci. 2009;81:686-92. http://dx.doi.org/10.1016/j.meatsci.2008.11.011

6. Vaquero MJR, Serravalle LRT, de Nadra MCM, de Saad Strasser AM. Antioxidant capacity and antibacterial activity of phenolic compounds from Argentinean herbs infusions. Food Control. 2010;21:779-85. http://dx.doi.org/10.1016/j.foodcont.2009.10.017

7. Georgantelis D, Ambrosiadis I, Katikou P, Blekas G, Georgakis SA. Effect of rosemary extract, chitosan and $\alpha$-tocopherol on microbiological parameters and lipid oxidation of fresh pork sausages stored at $4{ }^{\circ} \mathrm{C}$. Meat Sci. 2007;76:172-81. http://dx.doi.org/10.1016/j.meatsci.2006.10.026

8. Capitani CD, Hatano MK, Marques MF, Castro IA. Effects of optimized mixtures containing phenolic compounds on the oxidative stability of sausages. Food Sci Technol Int. 2012;19: 69-77.

http://dx.doi.org/10.1177/1082013212442184

9. Paraschos S, Mitakou S, Skaltsounis LA. Chios gum mastic: a review of its biological activities. Curr Med Chem. 2012;19: 2292-302 http://dx.doi.org/10.2174/092986712800229014

10. Rodriguez-Perez C, Quirantes-Pine R, Amessis-Ouchemoukh N, Mdani K, Segura-Carretero A, Fernandez-Gutierrez A. A metabolite-profiling approach allows the identification of new compounds from Pistacia lentiscus leaves. J Pharm Biomed Anal. 2013;77:167-74.

http://dx.doi.org/10.1016/j.jpba.2013.01.026

11. Hadjimbeil E, Botsaris G, Goulas V, Gekas V. Health promoting effects of Pistacia resins: recent advances, challenges and potential applications in the food industry. Food Rev Int.
2015;31:1-12.

http://dx.doi.org/10.1080/87559129.2014.938350

12. Cherbal A, Kebieche M, Madani K, El-Adawi H. Extraction and valorization of phenolic compounds of leaves of Algerian Pistacia lentiscus. Asian J Plant Sci. 2012;11:131-6. http://dx.doi.org/10.3923/ajps.2012.131.136

13. Goulas V, Exarchou V, Kanetis L, Gerothanassis IP. Evaluation of the phytochemical content, antioxidant activity and antimicrobial properties of mountain tea (Sideritis syriaca) decoction. J Funct Foods 2014;6:248-58. http://dx.doi.org/10.1016/j.jff.2013.10.014

14. Obied HK, Allen MS, Bedgood DR, Prenzler PD, Robards K. Investigation of Australian olive mill waste for recovery of biophenols. J Agric Food Chem. 2005;53:9911-20. http://dx.doi.org/ 10.1021/jf0518352

15. Orphanides A, Goulas V, Gekas V. Effect of drying method on the phenolic content and antioxidant capacity of spearmint. Czech J Food Sci. 2013;31:509-13.

16. Surveswaran S, Cai YZ, Corke H, Sun M. Systemic evaluation of natural phenolic antioxidants from 133 Indian medicinal plants. Food Chem. 2007;102:938-53. http://dx.doi.org/10.1016/j.foodchem.2006.06.033

17. Feddern V, Kupski L, Cipolatti EP, Giacobbo G, Mendes GL, Badiale-Furlong E, de Souza-Soares LA. Physico-chemical composition, fractionated glycerides and fatty acid profile of chicken skin fat. Eur J Lipid Sci Technol. 2010;112:1277-84. http://dx.doi.org/10.1002/ejlt.201000072

18. Qi S, Zhou D. Lotus seed epicarp extract as potential antioxidant and anti-obesity additive in Chinese Cantonese sausage. Meat Sci. 2013;93:257-62.

http://dx.doi.org/10.1016/j.meatsci.2012.09.001

19. Lorenzo JM, Franco D. Fat effect on physico-chemical, microbial and textural changes through the manufactured of dry-cured foal sausage lipolysis, proteolysis and sensory properties. Meat Sci. 2012;92:704-14. http://dx.doi.org/10.1016/j.meatsci.2012.06.026

20. Botsaris G, Taki A. Effect of high-pressure processing on the microbial quality throughout the shelf life of vacuum-packed sliced ham and frankfurters. J Food Process Preserv. 2015;39: $840-5$.

http://dx.doi.org/10.1111/jfpp.12294

21. ISO 4833-1:2013. Microbiology of the food chain - Horizontal method for the enumeration of microorganisms - Part 1: Colony count at 30 degrees $C$ by the pour plate technique. Geneva, Switzerland: International Organization for Standardization (ISO); 2013.

22. Galanakis CM, Goulas V, Tsakona S, Manganaris GA, Gekas V. A knowledge base for the recovery of natural phenols with different solvents. Int J Food Prop. 2013;16:382-96. http://dx.doi.org/10.1080/10942912.2010.522750

23. Atmani D, Chaher N, Berboucha M, Ayouni K, Lounis H, Boulaoud $\mathrm{H}$, et al. Antioxidant capacity and phenol content of selected Algerian medicinal plants. Food Chem. 2009;112: 303-9. http://dx.doi.org/10.1016/j.foodchem.2008.05.077

24. Sacchetti G, Maietti S, Muzzoli M, Scaglianti M, Manfredini S, Radice M, Bruni R. Comparative evaluation of 11 essential oils of different origin as functional antioxidants, antiradicals and antimicrobials in foods. Food Chem. 2005;91:621-32. http://dx.doi.org/10.1016/j.foodchem.2004.06.031

25. Magalhaes LM, Segundo MA, Reis S, Lima JLFC. Methodological aspects about in vitro evaluation of antioxidant properties. Anal Chim Acta 2008;613;1-19. http://dx.doi.org/10.1016/j.aca.2008.02.047

26. Frankel EN, Huang SW, Aeschbach R, Prior E. Antioxidant activity of rosemary extracts and its constituents, carnosic acid, carnosol, and rosmarinic acid, in bulk oil and oil-in water emulsion. J Agric Food Chem. 1996;44:131-5. http://dx.doi.org/10.1021/jf950374p 
27. Sørensen G, Jørgensen SS. A critical examination of some experimental variables in the 2-thiobarbituric acid (TBA) test for lipid oxidation in meat products. $\mathrm{Z}$ Lebensm Unters Forsch. 1996;202:205-10. http://dx.doi.org/10.1007/BF01263541

28. Igene JO, Pearson AM, Dugan JRLR, Price JF. Role of triglycerides and phospholipids on development of rancidity in model meat systems during frozen storage. Food Chem. 1980;5:263-76.

http://dx.doi.org/10.1016/0308-8146(80)90048-5
29. Trabelsi H, Sakouhi F, Renaud J, Villeneuve P, Khouja ML, Mayer P, Boukhchina S. Fatty acids, 4-desmethlsterols, and triterpene alcohols from Tunisian lentiscus (Pistacia lentiscus) fruits. Eur J Lipid Sci Technol. 2012;114:968-73. http://dx.doi.org/10.1002/ejlt.201100146

30. Lucera A, Costa C, Conte A, Del Nobile MA. Food applications of natural antimicrobial compounds. Front Microbiol. 2012;3:287.

http://dx.doi.org/10.3389/fmicb.2012.00287 